\title{
Phenolic Compounds and Antioxidant Potential of Nigerian Red Palm Oil (Elaeis Guineensis)
}

Sunday E. Atawodi (Corresponding author)

Biochemistry Department, Ahmadu Bello University, Zaria, Nigeria

Tel: 2348033850613 E-mail: atawodi_se@yahoo.com

Lazarus MD Yusufu

Surgery Department, Ahmadu Bello University Teaching Hospital, Zaria, Nigeria

Tel: 234-80-3593-0547

Joy C. Atawodi

Veterinary Public Health and Preventive Medicine, Ahmadu Bello University, Zaria

Tel: 234-80-360-9057

Oiza Asuku

Biochemistry Department, Ahmadu Bello University, Zaria, Nigeria

Tel: $234-70-3240-4225$

Ojochenemi E. Yakubu

Biochemistry Department, Ahmadu Bello University, Zaria, Nigeria

Tel: 234-80-6907-8726

Received: September 16, 2010 Accepted: September 30, 2010 doi:10.5539/ijb.v3n2p153

\begin{abstract}
Polyphenols have been shown in both in vitro and in vivo experiments to induce responses that are consistent with the protective effects of diets rich in fruits and vegetables against degenerative conditions such as cardiovascular disorders and cancer. Red palm oil, extracted from the fruit mesocarp of Elaeis guineensis is very important in the diet of many Nigerians, and indeed many citizens of developing countries living around the tropics. It contains antioxidant components such as carotenoids (alpha, beta, and gamma carotenes) and vitamin E (tocophorols and tocotrienols), which are of known nutritional and health benefits, but the antioxidant polyphenol contents of this oil is not fully explored. To assess the total antioxidant potential due partly to the scavenging of reactive oxygen specie (ROS) and the inhibition of the enzyme, xanthine oxidase, the hypoxanthine/xanthine oxidase assay system and the 2-deoxyguanosine-assay model were utilized. These revealed that the oil possesses promising antioxidant and radical scavenging activities with $\mathrm{IC}_{50}$ values of $95 \mu \mathrm{M}$ and $219 \mu \mathrm{M}$ for the hypoxanthine/xanthine oxidase and 2-deoxyguanosine assays, respectively. Liquid-Chromatography with Electrospray - Ionization Mass Spectrometry (LC-ESI) showed the presence of the antioxidant, 3,4 hydroxybenzyaldehyde, p-hydroxybenzoic acid, vanillic acid, syringic acid and ferulic acid in the red palm oil. Thus, in addition to antioxidant compounds like carotenoids, and vitamin E, the red palm oil also contains a rich mixture of phenolic compounds with potent antioxidant and radical scavenging capacities that might also account significantly for its widely reported capacity to modulate stress-related disorders.
\end{abstract}

Keywords: Palm oil, Elaeis guineensis, Antioxidant activity, Polyphenol

\section{Introduction}

Polyphenols have been shown in both in vitro and in vivo experiments to induce responses consistent with the protective effects of diets rich in fruits and vegetables against degenerative conditions such as cardiovascular 
diseases and cancer (F'guyer et al., 2003; Gupta and Mukhtar 2002; Linden et al., 2003; Stoner and Mukhtar, 1995; Yang et al., 2001; Nishino et al., 2000; Park and Pezzuto, 2002). For this reason, many foodstuffs, including oils from the low-incidence Mediterranean region have been assessed for polyphenol content as well as antioxidant potential (Owen et al., 2003; Owen et al., 2000a; Owen et al., 2000b). Oil that is very important in the diet of Nigerians and indeed many citizens of developing countries living around the tropics is the oil of the fruit mesopcarp of Elaeis guineensis, popularly known as the red palm oil.

The red palm oil is extracted from the mesocarp of ripened fruit of oil palm tree, Elaeis guineensis. The oil palm tree is native to many West African countries, including, Nigeria, where the oil used for culinary and other purposes, the sap as a popular wine, called palm wine; the trunk for building, and the leaf stalks as broom for sweeping; and branch stalk for making baskets and roof rafters. However, large scale plantations and traditionally owned wild plantations, established principally in tropical regions of Africa, Asia and Latin America, are mostly aimed at the production of red oil (Wattanapenpaiboon and Wahlqvist, 2003; Edem, 2002) which is widely recognized the most popular vegetable cooking oil in tropical west Africa (Edem, 2002; Elson,1992; Sundram et al., 2003).

Red palm oil is different from other plant and animal oils in that it contains $50 \%$ saturated fatty acids, $40 \%$ unsaturated fatty acids, and 10\% polyunsaturated fatty acids. The fruit also contains components such as carotenoids (alpha, beta, and gamma carotenes), vitamin E (tocophoreols and tocotrienols), sterols (sitosterol, stigmasterol and campesterol), phospholipids, glycolipids and squalene, which are of known nutritional and health benefits (Wattanapenpaiboon and Wahlqvist, 2003; Manorama and Rukmini (1991). In addition, it has been reported that certain powerful water-soluble antioxidants, phenolic acids and flavonoids can be recovered from the palm oil mill effluents (Abeywardena et al., 2002; Balasundram et al., 2003; Yun et al., 2008).

Owing to its high constituents of phytonutrients with antioxidant properties, the possibility exists that palm fruits and palm oil offers some health advantages by reducing lipid oxidation, oxidative stress and free radical-induced damage, which have been implicated in the etiology of several diseases, including cancer (Stoner and Mukhtar, 1995; Yang et al., 2001; Nishino et al., 2000) cardiovascular diseases gastrointestinal disorders diabetes neuro-degenerative disorders, Surh and Ferguson, 2003; Youdim and Joseph, 2000; Kinghorn et al 2004; Repetto and Llesuy, 2002), etc.

Tocotrienol-rich fraction of palm oil has been reported to activate p53, modulate $\mathrm{Bax} / \mathrm{BCl} 2$ ratio and induce apoptosis independent of cell cycle association, protects against aspirin-induced gastric lesions, suppress pre-neoplastic mammary epithelial cell proliferation, inhibit tumour promotion and protects cellular membrane against oxidative damage (Manorama et al., 1993; Balasundram et al., 2005; Ebong et al., 1999; Ong and Goh, 2002). The carotenoid fraction on the other hand, has been reported to chemoprevent and inhibits diesel exhaust-induced lung tumorigenesis, modulate the immune system by increasing peripheral blood natural killer (NK) cells and B-lymphocytes, and also suppress the growth of MCF-/ human breast cancer cells. Therefore, a great deal of studies on the antioxidant potential of red palm oil appears to have focussed on the tocopherol and carotenoids (Manorama et al., 1993; Balasundram et al., 2005; Ebong et al., 1999; Ong and Goh, 2002).

However, in the last decade, Abeywardena and co-workers (2002) reported that polyphenol-enriched extract of oil palm fronts promotes vascular relaxation via endothelium-independent mechanisms, lending further support to the potential cardiovascular actions of plant polyphenols, while Balasundram and colleagues (2003) identified sugars, gallic acids and 4-hydroxybenzoate with antiradical power from the phenolic-rich aqueous by-product fraction of oil plam milling. Beside these, reports on the phenolic content and antioxidant potential of phenolic-rich fraction of the red palm oil itself, which is prepared differently in various countries and civilizations, are hard to find. Hence, we examined the phenol-rich fraction of red palm oil, prepared by the Igala-style double extraction, for the polyphenol constituents, as well as its antioxidant and radical scavenging capacities.

\section{Materials and Methods}

\subsection{Samples}

An Igala-type red palm oil prepared by double extraction method to maximally limit levels of water - soluble impurities and moisture, was acquired from Agaliga-Imani village in Olamaboro Local Government Area of Kogi State, central Nigeria. The Palm oil was stored in glass bottle and transported to the laboratory of analysis in Heidelberg, Germany.

\subsection{Reagents}

Acetic acid, EDTA, hypoxanthine, methanol, xanthine, and xanthine oxidase were obtained from Merck (Darmstadt, Germany). $\mathrm{K}_{2} \mathrm{HPO}_{4}$ and $\mathrm{KH}_{2} \mathrm{PO}_{4}$ were obtained from Serva (Heidelberg, Germany). Formic acid, 
salicylic acid, and $\mathrm{FeCl}_{3} \cdot 6 \mathrm{H}_{2} \mathrm{O}$ were obtained from Aldrich Chemie (Steinheim, Germany). $N$-Methyl- $N$-(trimethylsilyl) trifluoro-acetamide (BSTFA) was obtained from Fluka (Buchs, Switzerland). Tetrabutylammonium hydroxide was obtained from Sigma Chemie (Deisenhofen, Germany). Standard phenolic compounds were obtained from laboratory stock, acquired from commercial sources, or isolated, purified, and characterized from natural sources. All solutions were made in double-distilled water.

\subsection{Extraction of phenolic compounds}

The phenolic compounds in the oil were extracted from the oil, basically as described by Owen and co-workers (Owen et al., 2003; Owen et al., 2000a; Owen et al., 2000b), but with minor modification. The oil (10g) was vortexed for $2 \mathrm{~min}$ at maximum speed in $50 \mathrm{ml}$ polyphylene bottles with $2 \mathrm{ml}$ methanol for 3 times. The mixture was centrifuged at $4000 \mathrm{rpm}$ for $30 \mathrm{~min}$, and methanol layer collected into graduated $20 \mathrm{ml}$ glass test tubes. Pooled methanol fractions were dried under nitrogen, taken up in $1 \mathrm{ml}$ acetonitrile, and lipid contaminants removed by vortexing with $3 \mathrm{X} 3 \mathrm{ml}$ hexane. The mixture was centrifuged at $3000 \mathrm{rpm}$ for $15 \mathrm{~min}$ each, and the hexane layer discarded. The acetonitrile layer was made up to $2.5 \mathrm{ml}$, and used for subsequent analysis (Fig.1).

\subsection{Analytical high-performance liquid chromatography (HPLC)}

Analytical HPLC was conducted on a Hewlett-Packard (Palo Alto, CA, USA) model 10980 liquid chromatograph fitted with a C-18 reverse-phase $(5-\mu \mathrm{m})$ column $(25 \mathrm{~cm} \times 4 \mathrm{~mm}$ i.d.) (Latex, Eppelheim, Germany). For separation of individual compounds in the extract, $2 \%$ acetic acid in water (solvent A) and methanol (solvent B) were used as mobile phase when $20 \mu \mathrm{L}$ of the extract was injected.

The solvent gradient consisted of $95 \%$ A for 2 minutes, $75 \%$ A in 8 minute, $60 \% \mathrm{~A}$ in 10 minute, $50 \%$ A in 10 minutes, and $0 \% \mathrm{~A}$ until completion of the run at 45 minutes The flow rate of the mobile phase was maintained at $1 \mathrm{~mL} /$ minute, and phenolic compounds in the eluate were detected with an ultraviolet dual-array detector (HP1040M, Hewlett-Packard) set at 278 and $340 \mathrm{~nm}$. Instrument control and data handling were by means of an HP Chemstation (Hewlett-Packard) operating in the Microsoft (Redmond, WA, USA) Windows software environment. The amount of phenolic compounds in the extracts was estimated by the external standard method (Owen et al., 2003; Owen et al., 2000a; Owen et al., 2000b).

\subsection{Hypoxanthine/xanthine oxidase assay}

To assess the total antioxidant potential due partly to the scavenging of reactive oxygen species and the inhibition of the enzyme xanthine oxidase, the hypoxanthine/xanthine oxidase assay system was used. In this assay, the extent of diphenol (2,5-dihydroxybenzoic acid and 2,3-dihydroxybenzoic acid) produced by hydroxyl radical (HO) attack on salicylic acid was measured from standard curves of their respective diphenols (Owen et al. 2000a; Owen et al. 2000b). The assay involves the re-suspension of different extract residues (prepared in duplicates by drying $0-500 \mu \mathrm{L}$ of extract solution) in $1 \mathrm{~mL}$ of phosphate buffer (pH 6.6). After addition of $5 \mu \mathrm{L}$ of xanthine oxidase $(20 \mu \mathrm{U} / 1.09 \mathrm{~mL})$, the tubes were incubated at $37^{\circ} \mathrm{C}$ for $3 \mathrm{~h}$, after which the reaction was stopped by addition of $5 \mu \mathrm{L}$ of concentrated $\mathrm{HCl}$. Where necessary, the reaction mixture was centrifuged at 10,000 rpm for 2 minutes in a Ficol Biofuge (Heraeus Instruments, Hanau, Germany), and $20 \mu \mathrm{L}$ of the mixture was analyzed by HPLC using the mobile phase and gradient condition noted above. The hydroxylation of hypoxanthine was monitored at $278 \mathrm{~nm}$, whereas the hydroxylation of salicylic acid was monitored at an absorbance of $325 \mathrm{~nm}$. The end products of the enzyme or free radical reaction were quantified against standard curves measured at the same wavelength.

\subsection{Deoxyguanosine assay for radical scavenging potential}

To evaluate the radical scavenging capacity of the extract, the 2-deoxyguanosine assay model was adopted. The buffer system is similar to that of the hypoxanthine/xanthine oxidase system, except that salicylic is replaced with 2-deoxyguanosine $(2 \mathrm{mM})$. The generation of reactive oxygen species was initiated by addition of ascorbic acid $(500 \mu \mathrm{M})$. Dried residues (of $0-500 \mu \mathrm{M}$ of extract solution prepared in duplicates) were re-suspended in buffer and incubated at $37^{\circ} \mathrm{C}$ for $24 \mathrm{~h}$. The assay of the 8-oxo-2-deoxyguanosine resulting from the reactive oxygen species attack on 2-deoxyguanosine was analyzed using an isocratic system consisting of $5 \%$ methanol and $95 \%$ aqueous buffer ( $5 \mathrm{~m} M$ tetra-butylammonium hydroxide, adjusted to $\mathrm{pH} 4.3$ with $6 \%$ formic acid). The ultraviolet detector was set at an absorbance of $293 \mathrm{~nm}$ (Owen et al., 2003; Owen et al., 2000a; Owen et al., 2000b).

\subsection{Determination of $50 \%$ inhibition of oxidation $\left(I C_{50}\right)$}

The amount of extracts producing the $\mathrm{IC}_{50}$ using the hypoxanthine/xanthine oxidase model system as well as the 2-deoxyguanosine assay methods was determined using the Table curve program (Jandel Scientific, Chicago, IL, USA). 


\subsection{Gas chromatography-mass spectrometry}

Analyses were performed on a HP 5973 mass spectrometer coupled to a HP 6890 gas chromatograph. Prior to gas chromatography-mass spectrometry analysis, dried methanolic extracts $(1 \mu \mathrm{M})$ were derivatized by addition of BSTFA $(100 \mu \mathrm{M})$ at $37^{\circ} \mathrm{C}$ for $30 \mathrm{~min}$. Separation of the analytes was achieved using an HP 5MS capillary column $(30 \mathrm{~m} \times 0.25 \mathrm{~mm}$ i.d., $0.25 \mu \mathrm{m}$ film thickness). Helium was used as the carrier gas with a linear velocity of $0.9 \mathrm{~mL} /$ second. The oven temperature program was as follows: initial temperature, $100^{\circ} \mathrm{C} ; 100-270^{\circ} \mathrm{C}$ at $4^{\circ} \mathrm{C} / \mathrm{min}$; and maintenance at $270^{\circ} \mathrm{C}$ for $20 \mathrm{~min}$. The gas chromatograph injector temperature was maintained at $250^{\circ} \mathrm{C}$; the transfer line temperature was held at $280^{\circ} \mathrm{C}$. The mass spectrometer parameters for electrospray ionization mode were as follows: ion source temperature, $230^{\circ} \mathrm{C}$; electron energy, $70 \mathrm{eV}$; filament current, 34.6 $\mu \mathrm{A}$; electron multiplier voltage, 1,200 V (Owen et al. 2003; Owen et al. 2000a; Owen et al. 2000b).

\subsection{Liquid chromatography-electrospray ionization mass spectrometry}

Liquid chromatography-electrospray ionization was conducted on an Agilent (Palo Alto) 1100 HPLC apparatus coupled to an Agilent LC/MSD apparatus (HP1101). Chromatographic separation was conducted using a C-18 reverse-phase (particle size, $5 \mu \mathrm{m})$ column $(25 \mathrm{~cm} \times 2 \mathrm{~mm}$ i.d.; Latex) using the same mobile phase and gradient as described for analytical HPLC, except that the flow rate was maintained at $0.5 \mathrm{~mL} / \mathrm{min}$. The analyses were conducted in the negative ion mode under the following conditions: dry gas (nitrogen) flow rate, $10 \mathrm{~L} / \mathrm{min}$; nebulizer pressure $=30 \mathrm{psi}$, drying gas temperature $=350^{\circ} \mathrm{C}$; capillary voltage $=2,500 \mathrm{~V}$; fragmenter voltage $=$ $100 \mathrm{~V}$; mass range $=50-3,000 \mathrm{Da} .2$ (Owen et al. 2003; Owen et al. 2000a; Owen et al. 2000b).

\section{Results}

\subsection{Polyphenol contents and antioxidant activity}

HPLC analysis revealed the presence of 3, 4-hydroxybenzyaldehyde, p-hydroxybenzoic acid, vanillic acid, syringic acid and ferulic acid in the red palm oil. Results of assay for antioxidant potential revealed that the oil possesses promising antioxidant and radical scavenging activities with IC50 values of $95 \mu \mathrm{M}$ and $219 \mu \mathrm{M}$ for the hypoxanthine/xanthine oxidase and 2-deoxyguanosine assays, respectively (Fig.2).

\section{Discussions and Conclusions}

The nutritional and health benefits of red palm oil have been a subject of intense research, especially because of its relevance to disease prevention in developing countries of the tropics. However, whereas, previous studies have concentrated on the antioxidant potential of the carotenoids and tocotrienols components of the oil (Wattanapenpaiboon and Wahlqvist, 2003; Edem, 2002; Elson,1992; Sundram et al., 2003; Ebong et al., 1999; Ong and Goh, 2002) the current results have demonstrated unequivocally, for the first time, that phenolic compounds with antioxidant properties, particularly, 3,4-hydroxybenzyaldehyde, p-hydroxybenzoic acid, vanillic acid, syringic acid and ferulic acid are also present in red palm oil, at least the Igala-style double extraction type obtained from Nigeria (Fig.2).

The presence of these phenolic compounds in palm oil is of major significance in disease prevention in the tropics, where this oil is widely consumed, since these compounds are potent antioxidants as reflected by the IC50 values of the oil when tested with the hypoxanthine/ xanthine and the 2-deoxyguanosine assay models (Fig.2). These phenolic acids are synthesized by a common pathway from phenylalanine involving polyketide pathway condensation reactions, and are credited for the health effects of several foodstuffs. This is not surprising, since individually the phenolic acids have been demonstrated to possess significant antioxidant properties. Owen and colleagues (2003) have demonstrated that p-hydroxybenzoic acid and ferulic acids are potent antioxidants with IC50 values of $1.69 \mu \mathrm{M}$ and $1.56 \mu \mathrm{M}$ respectively, while IC50 values for syringic acid and vanillic acids were $3.19 \mu \mathrm{M}$ and $2.7 \mu \mathrm{M}$ respectively.

p-Hydroxybenzoic acid and 3,4-dihydroxybenzaldehyde are important antioxidants in foods. With the exception of certain red fruits, black radish and onions, the hydroxybenzoic acid content of edible plants is generally low, but they are component of complex structures such as hydrolysable tannins (gallotannins in mangoes, and ellagitannins in strawberries and raspberries, respectively (Hannum, 2004; Chun et al 2003; Bravo 1998; Manach et al. 2004) Raspberries ellagitannins have been shown to inhibit 12-O-tetradecanoylphorbol-13-acetate (TPA)-induced ornithine decarboxylase, TPA-stimulated hydroperoxide production and TPA-stimulated DNA synthesis, and inhibited formation of the promutagenic adduct $\mathrm{O}^{6}$-methlyguanine by $73 \%$ and $80 \%$ respectively, after a single dose of N-nitrosomethylbenzyl-amine at $0.25 \mathrm{mg} / \mathrm{kg}$ (Park and Pezzuto, 2002). Despite this, it has not received attention with respect to its nutritional benefit until recent decades.

Other phenolic acid detected in palm oil are syringic acid and vanillic acid. These phenolic acids have been found to act synergistically with vitamin $\mathrm{C}$ to enhance human and hamster LDL resistance to oxidation (Chen et 
al., 2004) and indeed, inhibit the activities of two forms of phenolsulfotransferase enzymes involved in carcinogen sulfate conjugation (Yeh et al., 2004). They contribute to the antioxidant and anti-inflammatory properties of wine, cereals and other foodstuffs (Bravo, 1998; Lopez et al., 2003 Ross and Kasum, 2002; Hollman, 1996; Middleton, 2000). Other workers have demonstrated their ability to protect cultured skin cells from oxidative damage, inhibition of pancreatic lipase, protect against LDL oxidation, and possess antiproliferative and apoptotic effects on human breast cancer cells (Youdim and Joseph 2000; Kinghorn et al., 2004; Repetto and Llesuy et al., 2002).

According to Manach and colleagues (2004), ferulic acid, another phenolic found in palm oil, is also found most abundant in outer parts of cereal grains, like wheat $(0.8-2 \mathrm{~g} / \mathrm{kg}$ dry weight), where it is associated with the health benefit of barley, wheat and oat bran and rice bran (Ross and Kasum, 2002; Hollman et al., 1996; Middleton et al., 2000). An evaluation of ferulic acid and twenty three related compounds showed that ferulic acid possess stronger antioxidant activity than any of these related compounds. Other studies demonstrate that ferulic acids alleviates lipid peroxidation in diabetic rats, synergistically interact with other antioxidants to preserve physiological integrity of cells exposed to free radicals (Mathew and Abraham, 2004; Graf, 1992; Anselmi, 2004) and attenuates the processes that drive the pathology associated with Alzheimer's disease if the treatment is initiated before the neuroinflammatory processes can develop. In addition, ferulic acid protects against hydroxyl and peroxyl radical oxidation in synaptosomal and neuronal cell culture systems, as well as strongly inhibits arylamine $\mathrm{N}$-acetyltransferase activities in human gastrointestinal microflora (Mathew and Abraham 2004; Graf, 1992; Anselmi, 2004)

In conclusion, palm oil contains a rich mixture of phenolic compounds with potent antioxidant and radical scavenging activity to suggest that the widely reported capacity of palm oil to modulate the effect of oxidative stress on serum and antioxidant enzymes in membranes of liver and kidney, oxidative stress hypertension, suppress pre-neoplastic mammary epithelial cell proliferation, inhibit diesel-exhaust induced lung tumorigenesis, inhibit tumour promotion as well as modulate the immune system (Wattanapenpaiboon and Wahlqvist, 2003; Edem, 2002; Elson,1992; Sundram et al., 2003; Abeywardena et al., 2002; Balasundram et al., 2003; Yun et al., 2008) cannot be ascribed to their carotenoids and tocopherol components alone, but also to their antioxidant polyphenol contents.

\section{Acknowledgements}

SEA would like to thank Alexander von Humboldt Foundation (AvH), Bonn, Germany for grant of a research fellowship tenable at the Institute for Toxicology and Cancer Risk Factors, German Cancer Research Centre, Heidelberg, Germany in 2004/2005, and the subsequent material support award in respect of his scientific efforts. We thank Prof Dr H Bartsch and members of his group particularly, Drs B Spiegelhalder, R.W Owen and B.Pfundstein for hosting the analytical aspect.

\section{References}

Abeywardena, M, Runnie I, Nizar, M, Suhaila M, Head R. \& Momamed S. (2002). Polyphenol-enriched extract of oil palm fronds (Elaeis guineensis) promotes vascular relaxation via endothelium-dependent mechanisms. Asia Pacific Journal Clinical Nutrition, 11 Suppl. 7, S467-72.

Anselmi, C., Centini, M., \& Granata P. (2004). Antioxidant activity of ferulic acid alkyl esters in a heterophasic system: a mechanistic insight. Journal Agriculture Food Chemistry, 52(21), 6425-6432.

Balasundram N, Ai TY, Sambanthamurthi R, Sundram K, \& Samman S. (2005). Antioxidant properties of palm fruit extracts . Asia Pacific Journal Clinical Nutrition, 14(4), 319-324.

Balasundram, N, Bubb W, Sundram K, \& Samman S. (2003). Antioxidants from palm (Elaeis guineensis) fruit extracts Asia Pacific Journal Clinical Nutrition, 12 Suppl, S37

Bravo, L. (1998) Polyphenols: chemistry, dietary sources, metabolism, and nutritional significance. Nutrition Review, 56, 317-333.

Chen, C. Y., Milbury, P. E., \& Kwak, H. K. (2004). Avenanthramides and phenolic acids from oats are bioavailable and act synergistically with vitamin $\mathrm{C}$ to enhance hamster and human LDL resistance to oxidation. Journal of Nutrition, 134(6), 1459-1466.

Chun, O.K., Kim D.O., Moon H.Y, Kang H.G, \& Lee C.Y. (2003). Contribution of individual polyphenolics to total antioxidant capacity of plums. Journal Agriculture Food Chemistry, 51, 7240-7245.

Ebong P.E., Owu D.U., Isong E.U. (1999). Influence of palm oil (Elaesis guineensis) on health. Plant Foods for Human Nutrition., 53(3), 209-222 
Edem D.O. (2002). Palm oil: biochemical, physiological, nutritional, hematological, and toxicological aspects: a review. Plant Foods for Human Nutrition, 57(3-4), 319-341.

Elson CE (1992) Tropical oils: nutritional and scientific issues. Critical Review on Food Science and Nutrition. 31(1-2), 79-102.

F'guyer, S., Afaq, F., \& Mukhtar, H. (2003). Photochemoprevention of skin cancer by botanical agents. Photodermatolology, Photoimmunolology and Photomedicine, 19, 56-72

Graf, E. (1992). Antioxidant potential of ferulic acid. Free Radicals in Biology and Medicine, 13(4), 435-448.

Gupta, S, \& Mukhtar, H. (2002). Chemoprevention of skin cancer: current status and future prospects. Cancer Metastasis Review, 21, 363-380.

Hannum S.M. (2004) Potential impact of strawberries on human health: a review of the science. Critical Review on Food Science and Nutrition, 44, 1-17.

Hollman, P.C., \& Katan M.B. (1999). Health effects and bioavailability of dietary flavonols. Free Radicals in Biology and Medicine, 31(Suppl), S75-S80.

Hollman, P.C., Hertog, M.G., \& Katan M.B. (1996). Role of dietary flavonoids in protection against cancer and coronary heart disease. Biochemistry Society Transactions., 24, 785-789.

Kinghorn, A.D., Su, B.N., Jang, D.S, Chang, L.C, Lee, D, Gu, J.Q, Carcache-Blanco, E.J., Pawlus, A.D., Lee, S.K., Park, E.J., Cuendet, M., Gills, J.J., Bhat, K., Park, H.S., Mata-Greenwood, E., Song, L.L., Jang, M., \& Pezzuto. J.M. (2004). Natural inhibitors of carcinogenesis. Planta Medica, 70, 691-705.

Linden, K.G, Carpenter, P.M, McLaren C.E, Barr, R.J, Hite, P, Sun, J.D, Li, K.T., Viner, J.L., \& Meyskens, F.L. (2003). Chemoprevention of nonmelanoma skin cancer: experience with a polyphenol from green tea. Recent Results in Cancer Research, 163, 165-171.

Lopez-Velez, M., Martinez-Martinez, F., \& Valle-Ribes C. (2003). The study of phenolic compounds as natural antioxidants in wine. Critical Review in Food Science and Nutrition, 43, 233-244.

Manach, C., Scalbert, A., \& Morand, C. (2004). Polyphenols: food sources and bioavailability, American Journal Clinical Nutrition., 79(5), 727-747

Manorama, R. \& Rukmini, C. (1991) Nutritional evaluation of crude palm oil in rats. American Journal Clinical Nutrition, 53(4 Suppl), 1031S-1033S.

Manorama, R., Chinnasamy, N., \& Rukmini, C. (1993). Effect of red palm oil on some hepatic drug-metabolizing enzymes in rats. Food and Chemical Toxicology, 31(8), 583-588.

Mathew, S., \& Abraham, T.M. (2004) Ferulic acid: an antioxidant found naturally in plant cell walls and feruloyl esterases involved in its release and their applications. Critical Review Biotechnology., 24(2-3), 59-83.

Middleton, E., Kandaswami, C.,\& Theoharides, T.C. (2000). The effects of plant flavonoids on mammalian cells: implications for inflammation, heart disease, and cancer. Pharmacol Rev., 52, 673-751.

Nishino, H., Tokuda, H., Satomi, Y., Masuda, M., Onozuka, M., Yamaguchi, S., Takayasu, J., Tsuruta, J., Takemura, M., Ii, T., Ichiishi, E., Kuchide, S., Okuda, M., \& Murakoshi, M. (2000). Cancer chemoprevention by phytochemicals and their related compounds. Asian Pacific Journal Cancer Preview, 1, 49-55.

Ong, A.S., \& Goh, S.H. (2002). Palm oil: a healthful and cost-effective dietary component. Food and Nutrition Bulletin. 23(1), 11-22.

Owen, R.W, Giacosa, A., Hull, W.E., Haubner, R., Spiegelhalder B., \& Bartsch, H. (2000a). The antioxidant/anticancer potential of phenolic compounds isolated from olive oil. European Journal of Cancer, 36, $1235-1247$.

Owen, R.W., Haubner, R., Mier, W, Giacosa A, Hull, W.E., Spiegelhalder, B, \& Bartsch, H. (2003). Isolation, structure elucidation and antioxidant potential of the major phenolic and flavonoid compounds in brined olive drupes. Food and Chemical Toxicology, 41,703-717.

Owen, R.W., Mier, W., Giacosa, A., Hull, W.E., Spiegelhalder, B.,\& Bartsch, H. (2000b). Phenolic compounds and squalene in olive oils: the concentration and antioxidant potential of total phenols, simple phenols, secoiridoids, lignans and squalene. Food and Chemical Toxicology, 38, 647-659

Park, E.J, \& Pezzuto J.M. (2002). Botanicals in cancer chemoprevention. Cancer Metastasis Review, 21, $231-255$. 
Repetto, M.G., \& Llesuy, S.F. (2002). Antioxidant properties of natural compounds used in popular medicine for gastric ulcers. Brazilian Journal of Medical and Biological Research, 35, 523-534.

Ross, J.A., \& Kasum C.M. (2002). Dietary flavonoids: bioavailability, metabolic effects, and safety. Annual Review of Nutrition, 22, 19-34.

Stoner, G.D, \& Mukhtar H. (1995). Polyphenols as cancer chemopreventive agents. Journal of Cell Biochemistry, (Suppl 22), 169-180

Sundram, K., Sambanthamurthi, R., \& Tan, Y.A. (2003). Palm fruit chemistry and nutrition. Asia Pac J Clin Nutr., 12(3), 355-362.

Surh, Y.J, \& Ferguson, L.R. (2003). Dietary and medicinal antimutagens and anticarcinogens: molecular mechanisms and chemopreventive potential-highlights of a symposium. Mutat Res, 523-524, 1-8.

Wattanapenpaiboon, N, \& Wahlqvist M.W. (2002). Phytonutrient deficiency: the place of palm fruit. Asia Pacific Journal of Clinical Nutrition, 12(3), 363-368.

Yang, C.S., Yang, G.Y., Landau, J.M., Kim, S., \& Liao, J. (1998). Tea and tea polyphenols inhibit cell hyperproliferation, lung tumorigenesis, and tumor progression. Experimental Lung Research, 24, 629-639.

Yeh, C.T., Shih, P.H., \& Yen, G.C. (2004). Synergistic effect of antioxidant phenolic acids on human phenolsulfotransferase activity. Jornal of Agriculture and Food Chemistry, 52(13), 4139-4143.

Youdim, K.A., \& Joseph, J.A. (2001). A possible emerging role of phytochemicals in improving age-related neurological dysfunctions: a multiplicity of effects. Free Radicals in Biology and Medicine, 30, $583-594$.

Yun, P.N., Ariffin, A., Tan C.P \&Yew, A.I. Tan, Y.W. (2008). Determination of oil palm fruit phenolic compounds and their antioxidant activities using spectrophotometric methods Internl Journal of Food Science \& Technology, 43(10), 1832-1837. 


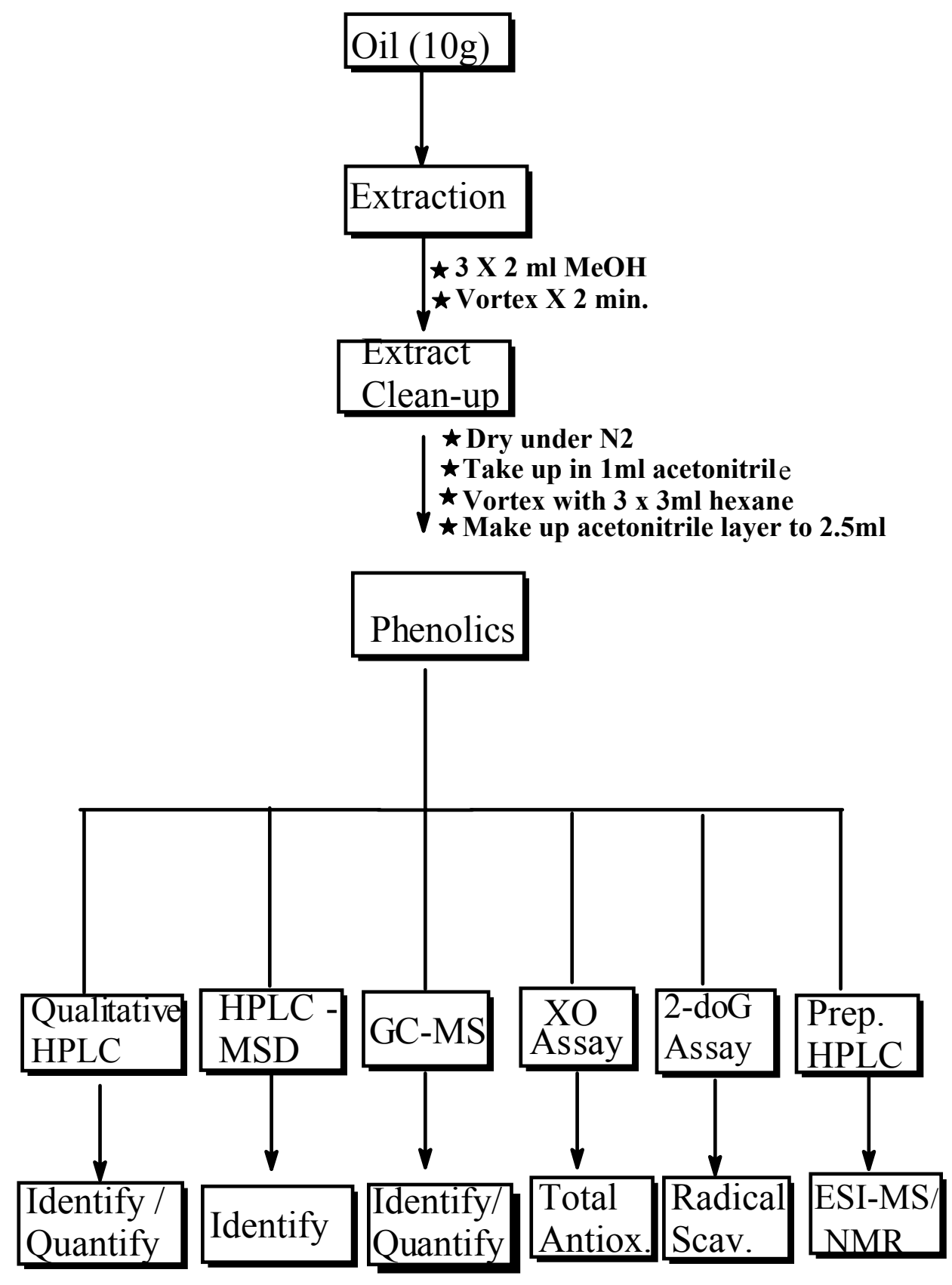

Figure 1. Analytical scheme for extraction, identification and in vitro antioxidant activity of Elaeis guineensis oil 


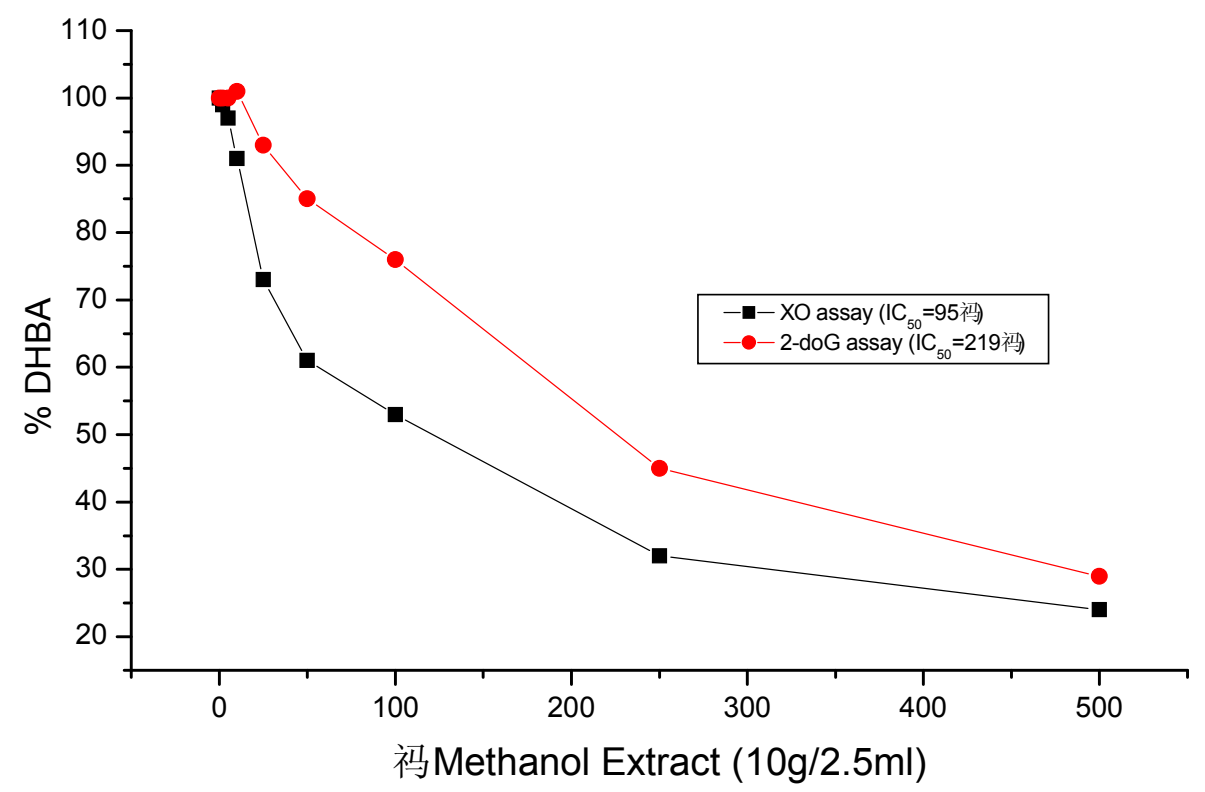

Figure 2. In vitro evaluation of the antioxidant and radical scavenging potential of methanol extract of Elaeis guineensis using the xanthine oxidase and 2-deoxyguanosine assay models 